\title{
A ANTINOMIA REAL E A POLÊMICA DO DIÁLOGO DAS FONTES
}

\section{THE REAL ANTINOMY AND THE CONTROVERSY OVER DIALOGUE OF SOURCES}

\section{MARIA HELENA DINIZ}

Mestre e doutora em Teoria Geral do direito e Filosofia do Direito pela Pontifícia Universidade Católica de São Paulo - PUCSP. Livre-Docente e Titular de direito civil da Pontifícia Universidade Católica de São Paulo - PUCSP, por concurso de títulos e provas. Professora de Filosofia do Direito, de Teoria Geral do Direito e de Direito Civil Comparado nos cursos de Pós-Graduação em Direito da Pontifícia Universidade Católica de São Paulo - PUCSP. Coordenadora do Núcleo de Pesquisa em Direito Civil Comparado nos cursos de Pós-Graduação em Direito da Pontifícia Universidade Católica de São Paulo - PUCSP. Professora de Direito Civil no curso de Graduação em Direito da Pontifícia Universidade Católica de São Paulo - PUCSP. Membro da Academia Paulista de Direito da Academia Notarial Brasileira, do Instituto dos Advogados de São Paulo e do Instituto de Direito Comparado LusoBrasileiro. Presidente do Instituto Internacional de Direito.

\section{RESUMO}

Neste artigo, apenas, traçaremos considerações científicas ou técnicas sobre a questão dos conflitos normativos e da polêmica criada pela teoria do diálogo das fontes de Erik Jayme, temas que engendram complexidade por não estarem bem estruturados doutrinariamente. Ante a impossibilidade de o legislador conhecer todas as normas existentes no ordenamento jurídico é plausível a edição de normas antinômicas. A existência de conflitos normativos consiste num convite para esclarecer não só os limites e as funções do jurista e do aplicador em prol da 
solução das antinomias aparentes, e reais, mas também o papel exercido pelo dialogo das fontes na interpretação corretiva.

PALAVRAS-CHAVES: Antinomia aparente; Antinomia real; Critérios e metacritérios solucionadores; Diálogo das fontes; Interpretação corretivo; equitativa.

\begin{abstract}
In this article, we will only draw scientific or technical considerations on the issue of normative conflicts and the controversy created by Erik Jayme's theory about the dialogue of sources, themes that engender complexity because they are not well structured doctrinally. Given the impossibility of the legislator to know all the existing norms in the legal system, it is plausible to issue antinomic norms. The existence of normative conflicts consists of an invitation to clarify not only the limits and functions of the jurist and the applicator in favor of the solution of the apparent and real antinomies but also the role played by the dialogue of sources in the corrective interpretation.
\end{abstract}

KEYWORDS: Apparent antinomy; Real antinomy; Solving criteria and metacriteria; Dialogue of sources; Corrective; equitable interpretation.

\title{
INTRODUÇÃO: CONFLITO NORMATIVO COMO PROBLEMA TEÓRICO
}

O que é antinomia real?

Questão bastante controvertida, pois para seu devido equacionamento não há, na doutrina, critérios coordenados e seguros para sua elucidação, ante:

a) a existência de opiniões dispares dos jusfilósofos a respeito;

b) o fato de que muitos teóricos do direito ainda não se conscientizaram do problema e da solução que a ciência jurídica pode oferecer. 
c) a incompletude e inconsistência dos meios de sua solução (DINIZ, 2017, p.13).

O sistema jurídico é o resultado de uma atividade científica que congrega os elementos do direito (repertório), estabelecendo as relações entre eles (estrutura), albergando uma referência à mundividência que animou o jurista, elaborador desse sistema (FERRAZ JR, 1978b, p.141; ENGISCH, 1964, p.27).

Os tridimensionalistas entendem que as normas são partes de um âmbito maior, que é o direito, sendo assim não esgotam a totalidade do direito, nem podem identificar-se com ele. O direito seria uma ordenação heterônoma das relações sociais, baseado numa integração normativa de fatos e valores (REALE, 1973, p.67).

Assim, na tridimensionalidade jurídica de Miguel Reale, encontramos a noção de que o sistema jurídico, criado pelo jurista, compõe-se de um subsistema de normas, de um subsistema de fatos e de um subsistema de valores, isomórficos entre si, pois deve haver uma igualdade estrutural ou correlação entre eles (KLUG, 1961, p.129).

Dessas ideias deduzimos que os elementos do sistema estão vinculados entre si por uma relação, sendo interdependentes. Se houver incongruência entre eles, temos quebra de isomorfia e lacuna, se conflito dentro do subsistema normativo, temos antinomia.

A lacuna constitui o estado incompleto do sistema, que deve ser colmatado ante os princípios da plenitude do sistema jurídico e da unidade epistemológica de conjuntos (FERRAZ JR, 1978b, p.141; ROSENTREICH, 1963, p.21, 24 e 179).

Esse princípio da unidade pode levar-nos à questão da correção do direito incorreto. Se se apresentar uma antinomia real ou um conflito de normas, igualmente fortes, igualmente validas, ter-se-á um estado incorreto do sistema, que precisara ser solucionado, pois o postulado desse principio é o da resolução das contradições (ENGISCH, 1964, p.253).

O sistema jurídico deverá, teoricamente, formar um todo coerente, devendo por isso, excluir qualquer contradição lógica nas asserções, feitas pelo jurista, elaborador do sistema sobre as normas, para assegurar sua homogeneidade e garantir a segurança na aplicação do direito (BUCH, 1965, p.390-391). Para tanto, o 
jurista lançara mão de uma interpretação corretiva, guiado pela interpretação sistemática, e pelo diálogo das fontes, que o auxiliarão na pesquisa dos critérios, para solucionar a antinomia, a serem utilizados pelo aplicador do direito (GAVAZZI, 1959, p.166-168). A esse esforço ou arte os Estatutos da Universidade de Coimbra de 1772, denominavam terapêutica jurídica (MAXIMILIANO, 1965, p.134).

Trata-se de um desenvolvimento aberto do direito dirigido metodicamente, que se mantém dentro dos limites marcados pelo ordenamento jurídico que é mais rico de conteúdo do que as disposições normativas, pois contém ideias jurídicas, critérios valorativos e fáticos. O jurista, ao construir o sistema jurídico teria, na lição de Bobbio (1965, p.237), a tarefa de apontar critérios para reconhecer a antinomia e para sua resolução pelo juiz, que não pode eximir-se de sentenciar.

Se se investiga o direito como um fenômeno dinâmico, pode-se verificar que a antinomia aparece fora da ocasião da decisão judicial, pois pode ser detectada num momento anterior e solucionada pelo Legislativo.

O Juiz resolve a antinomia, mas sua decisão não implica a solução da antinomia, pois somente pretende evitar o prosseguimento desse conflito normativo num dado caso singular. Tal conflito permanece latente dentro do ordenamento até que o Legislador o solucione (DINIZ, 2014, p.27-29).

\section{CONCEITO DE ANTINOMIA REAL E AS CONDIÇÕES NECESSÁRIAS À SUA CONFIGURAÇÃO}

Segundo Tércio Sampaio Ferraz Jr. antinomia real é a oposição total ou parcial que ocorre em duas normas, emanadas de autoridades competentes num mesmo âmbito normativo que coloca o sujeito (aplicador) numa posição insustentável pela ausência ou inconsistência de critérios aptos a permitir-Ihe uma saída nos quadros de um dado ordenamento (FERRAZ JR, 1978b, p.14).

Trata-se de uma lacuna de conflito ou de colisão, como diz Klug (1965, p.8689), porque, em sendo conflitantes as normas se excluem reciprocamente, por ser impossível a remoção da contradição, pela dificuldade de destacar uma como a mais 
forte, por não haver critério normativo que permite decidir entre elas, obrigando o magistrado a solucionar o caso sub judice, segundo os critérios de preenchimento de lacunas.

Para que haja real incompatibilidade entre duas normas será preciso que (FERRAZ JR, 1978b, p.13-14; GAVAZZI, 1959, p.50; PERELMAN, 1965, p.392):

a) ambas as normas conflitantes sejam jurídicas. Não há conflito entre uma norma moral e uma norma jurídica, porque a relação entre elas expressa um conflito de deveres, sob o prisma moral e não sob o ponto de vista jurídico. Não se pode falar em conflito ou incompatibilidade jurídica entre duas normas de ordenamentos diferentes, uma do ordenamento normativo moral e outra do jurídico.

b) ambas sejam vigentes e pertencentes a um mesmo ordenamento jurídico. Logo, um estudioso do direito comparado não poderia dizer que 0 artigo $X$ do Código Civil português é incompatível com o artigo $Y$ do Código Civil brasileiro, apenas poderia mostrar as diferenças e semelhanças que tais dispositivos legais apresentam.

c) ambas devem emanar de autoridades competentes num mesmo âmbito normativo, prescrevendo ordens ao mesmo sujeito.

d) ambas devem ter operadores opostos (uma permite, outra proíbe) e os seus conteúdos (atos e omissões) devem ser a negação interna um do outro, isto é uma prescreve o ato e a outra a omissão. São antinômicas a norma $A$ que prescreve é permitido fumar neste recinto, e a $B$ que reza é obrigatória a omissão de fumar neste recinto.

e) o sujeito, a quem se dirigem as normas conflitantes, deve ficar numa posição insustentável, por faltarem critérios normativos solucionados.

Em suma para haver antinomia real será preciso a concorrência de três condições que são: incompatibilidade, indecibilidade e necessidade de decisão. 


\section{CLASSIFICAÇÃO DAS ANTINOMIAS}

Pode-se classificar as antinomias quanto (ROSS, 1970, p.124; BOBBIO, 1960, p.92-95; FERRAZ JR, 1978b, p.14-18; DINIZ, 2014, p.37-43, 75-79, 93-114, 125-128; SILANCE, 1965, p.64; SALMON, 1965, p.285; VANDER ELST, 1965, p.138; ENGISCH, 1964, p.253-267):

A) Ao critério de solução. Hipótese em que se terá:

a) Antinomia aparente, se os critérios para solucioná-la forem normas integrantes do ordenamento jurídico, logo não se teria de recorrer a critérios interpretativos não normativos. O intérprete ou o aplicador poderá conservar as duas normas incompatíveis, optando por uma delas. Tal conciliação se dá por meio da subsunção, mediante simples interpretação, aplicando-se um dos critérios de solução fornecidos pelo próprio ordenamento jurídico (cronológico, hierárquico ou o da especialidade). P. ex. pelo art. 835, do CC brasileiro, o fiador poderá exonerarse da obrigação, a todo tempo, se a fiança tiver duração ilimitada, mas ficará obrigado por todos os efeitos da fiança durante 60 dias após a notificação do credor, mas se a fiança for prazo determinado, só se desligará dela com o vencimento do prazo. Pela Lei 8245/91, art. 39, o fiador permanecerá responsável pelos alugueis e acessórios da locação até a efetiva devolução das chaves do imóvel urbano locado, mesmo que haja prorrogação da locação por prazo determinado.

Se o bem locado for imóvel urbano, a fiança que garante a locação rege-se pelo art. 39, da Lei n. 8245/91, por ser norma especial (CC. Art. 2036). O CC art. 835 só se aplicaria a fiança garantidora de locação de outros tipos de bens.

b) Antinomia real, se não houver na ordem jurídica qualquer critério normativo para sua solução, sendo então imprescindível, uma interpretação corretiva-equitativa ou a edição de uma nova norma que escolha uma das normas conflitantes para sua eliminação.

A solução dada pelo órgão judicante aplicar-se-á apenas ao caso sub judice.

P. ex. pelo $5^{\circ}$ da CF, todos são iguais perante a lei. O art. 100 CF diz que credores da Fazenda Pública deverão ser pagos na ordem cronológica de pagamento. $\mathrm{O}$ art. 33 do Ato das Disp. Transitórias reza que "ressalvados os créditos 
de natureza alimentar, o valor dos precatórios judiciais pendentes de pagamento na data da promulgação da CF poderá ser pago no prazo de 8 anos. E o art. 78 do ADT dispõe que precatórios pendentes na data da EC 30/2000, ajuizados até 31/12/99 deverão ser pagos no prazo máximo de 10 anos, e no $\S 3^{\circ}$ reduz para 2 anos, se precatório for oriundo de desapropriação de imóvel residencial do credor.

Tais artigos estão tratando desigualmente os iguais (credores da Fazenda Pública, dando azo a uma antinomia real, por não haver critério normativo solucionador, pois as normas conflitantes são da mesma hierarquia, entraram em vigor na mesma data, apesar da ocorrência posterior alteração da EC n. 62/2009, que altera a redação do art. 97 do ADT, dando prazo de 15 anos para pagamento de precatório de dívidas alimentares a pessoa com mais de 60 anos de idade. Nem do especialidade poderá ser aplicado pois exige que se trate desigualmente o que é desigual. $O$ hierárquico também não (todas as normas conflitantes são constitucionais), nem o cronológico (todas entraram em vigor no mesmo dia).

Por meio de uma interpretação corretiva, aplicando-se a LINDB arts. $4^{\circ}$ e $5^{\circ}$ optar-se-ia p. ex. pelo art. 100 que deverá prevalecer sobre os arts., 33, 78 e 97, atendo-se ao princípio da isonomia.

B) Ao conteúdo (Engisch) . Ter-se-á:

a) Antinomia própria se um comportamento aparecer ao mesmo tempo proibida e não proibida: P. ex: se o Código Militar prescreve obediência incondicionada a ordens de um superior e disposição do Código Penal proíbe certos atos (matar, privar alguém da liberdade), quando um capitão ordena o fuzilamento ou a prisão de um prisioneiro de guerra, o soldado se vê às voltas com duas normas conflitantes, a que o obriga a cumprir ordens de seu superior e a que o proíbe p. ex. de matar ou prender um ser humano.

Somente uma delas poderá ser aplicada e esta será determinada por critério normativo (no caso o da especialidade);

b) antinomia imprópria (Karl Engusch), se ocorrer em virtude do conteúdo material das normas, podendo apresentar-se como: 
b.1. antinomia de princípios se houver desarmonia numa ordem jurídica pelo fato dela fazerem parte diferentes ideias fundamentais entre as quais se pode estabelecer um conflito: P. ex. quando as normas de um ordenamento jurídico protegem valores opostos, como liberdade, justiça e segurança. Pode ocorrer que um deles seja sacrificado total ou parcialmente, por isso há imposição de limites considerando-se a pessoa, a idade, a situação, prazo. P. ex. pode parecer injusto, como diz Engisch, que alguém pratique atos indecorosos com uma jovem de 13 anos seja punido severamente enquanto outro, que faz o mesmo com uma moça de 15 anos, imatura, fique impune (no Brasil tal não ocorre ante CPC, art. 216-A, $\S 2^{\circ}$ ). Mas às vezes, conforme o caso, a segurança deixa de ter relevância, cedendo à justiça.

b.2. antinomia valorativa, se o legislador não for fiel a uma valoração por ele própria realizada, pondo-se em conflito com as próprias valorações. P. ex. quando prescreve pena mais leve para delito mais grave. Se uma norma do Código Penal punir menos severamente o infanticídio, morte voluntária de criança pela mãe no momento do parto ou logo após o nascimento, a exposição de criança a perigo de vida mediante enjeitamento, do que o homicídio, surge esse tipo de antinomia, que deve ser tolerada pelo aplicador, apesar valor "vida" ser o mesmo.

b.3. antinomia teleológica se se apresentar incompatibilidade entre os fins propostos por certa norma e os meios para a consecução daqueles fins. O legislador quer um fim, mas com outra norma retira os meios para atingir aquele fim. P. ex. Código Civil art. 100 prescreve que os bens públicos são inalienáveis, salvo se lei permitir sua venda.

b.4. antinomia técnica, atinente à falta de uniformidade da terminologia legal. P.ex. a palavra posse em direito civil tem sentido diverso em direito administrativo.

Tais antinomias são impróprias porque não impedem que o sujeito aja conforme as normas.

C) ao âmbito pode-se ter: 
c.1. antinomia de direito interno, que ocorre entre normas de um ramo direito (n. de civil conflitando com outra de civil) ou entre normas de diferentes ramos jurídicos ( norma de direito administrativo conflitando com norma constitucional);

c.2. antinomia de direito internacional que surge entre normas de direito internacional público, ou seja, entre Tratados ou convenções internacionais, costumes internacionais normas criadas pelas organizações internacionais e

c.3. antinomia de direito interno-internacional, que surge entre uma norma de direito interno (CF art. 5ำ, inciso 67 p. ex) e uma norma de direito internacional público ( Pacto de S. Jose).

D) à extensão da contradição. Segundo Alf Ross, ter-se-á:

d.1. antinomia total-total se uma das normas não puder ser aplicada em nenhuma circunstância sem conflitar com outra. P. ex. norma que prescreve que é proibido fumar e outra que estatui é permitido fumar;

d.2. antinomia total-parcial, se uma das normas não puder ser aplicada em nenhuma circunstância sem conflitar com a outra, que com ela conflita em parte. P. ex. uma diz, é proibido fumar, e outra, é permitido fumar cachimbo; estrangeiros não podem pescar em águas territoriais brasileiras, e outra estabelece que poderão pescar desde que domiciliados no Brasil há mais de dois anos e

d.3. antinomina parcial- parcial, quando as duas normas só em parte conflitarem uma com a outra. P. ex. O art. 543 do CC prescreve que doação pura e simples a absolutamente incapaz dispensa aceitação, conflita com o art. 1748, II, do CC, que reza que tutor deve aceitar expressamente doação feita a tutelado ainda que com encargo. A primeira diz-respeito a quem estiver sob o poder familiar apenas. 


\section{CRITÉRIOS PARA A SOLUÇÃO DOS CONFLITOS NORMATIVOS APARENTES}

Os critérios para solução das antinomias não são princípios lógicos, assim como o conflito não é uma configuração lógica. São critérios normativos, princípios jurídico-positivos ${ }^{1}$.

Os critérios normativos para solução de antinomias de direito interno são (BOBBIO, p. 237-58. FERRAZ JR., 1978b, p. 14):

a) o hierárquico ("lex superior derogat legi inferiori") previsto na CF - 59, baseado na superioridade de uma fonte de produção jurídica sobre a outra. $O$ principio lex superior quer dizer que em um conflito entre normas de diferentes níveis, a de nível mais alto, qualquer que seja a ordem cronológica, terá preferência em relação à de nível mais baixo. Assim p. ex. a norma constitucional prevalecerá sobre uma lei;

b) O cronológico ("lex posteriori derogat legi priori", que se remonta ao tempo em que as normas começaram a ter vigência, restringindo-se somente ao conflito de normas pertencentes ao mesmo escalão. Logo, a ultima prevalece sobre a anterior, se com ela for incompatível, respeitando-se ato jurídico perfeito, direito adquirido e coisa julgada (LINDB, art. $2^{\circ} \S 1^{\circ} \mathrm{CF}, 5^{\circ}, \mathrm{XXXVI)}$ e

c) o da especialidade (lex specialis derogat legi generalis), que visa a consideração da matéria normada, com o recurso dos meios interpretativos. Uma norma é especial se possuir em sua definição legal todos os elementos típicos da norma geral e mais alguns de natureza objetiva ou subjetiva, denominados especializantes. Há uma diversificação do desigual. Tratamento desigual ao desigual, (segunda parte do principio da isonomia, CF art. 5) fazendo as diferenciações exigidas fática e axiologicamente. Realmente se, em certas circunstâncias, uma norma ordena ou permite determinado comportamento somente a algumas pessoas, as demais, em idênticas situações, não são alcançadas por ela, por se tratar de disposição excepcional, que só vale para as situações normadas.

\footnotetext{
1 BOBBIO., 1965. p. 244 e 250; MERKL, 1927. p. 211; MERKL, 1917, afirma que o princípio lex posterior derogat legi priori não é um principio lógico, mas uma norma de direito positivo.
} 
Princípios para resolução dos conflitos entre normas de direito internacional público por ex. (tratados):

a) Priori in tempore potior in jus, que dá, havendo conflito entre dois tratados, preferência ao primeiro sobre o segundo, desde que os dois não tenham sido elaborados pelas mesmas partes. Trata-se do princípio da primazia da obrigação anteriormente assumidas.

b) Lex posterior derogat priori, que se aplica sempre que o segundo tratado dita a lei dos Estados signatários do primeiro. Como o segundo tratado não é res inter alios acta haverá derrogação expressa ou tácita do primeiro.

c) Lex specialis derogat generale, aplicável apenas nos casos de tratados sucessivos entre os mesmos signatários.

d) Lex superior derogat inferiori, pelo qual a norma superior se liga não a natureza da fonte, mas ao valor por ela colimado. P. ex. um tratado que concretize o valor ordem pública internacional deverá prevalecer contra a que visa a mera segurança de um dos contratantes; a Carta das Nações Unidas deverá ter preferência ante um tratado em que dois países concertam assuntos que só a eles interessam (SALMON, 1965. p. 285-314; FERRAZ JR., 1978b. p. 16-17).

Critérios para resolução dos conflitos entre normas de direito internacional público e norma de direito interno.

Nos conflitos entre norma de direito internacional e norma de direito interno (SALMON, 1965, p. 315-319; FERRAZ JR., 1978b, p. 17; MAREK, p. 260-298, 1962) que ocorrem quando uma lei interna contraria um tratado internacional, a jurisprudência consagrará a superioridade da norma internacional sobre a interna, se esse conflito for submetido a um juízo internacional. Mas se for levado à apreciação do Juízo interno, poderá reconhecer:

a) a autoridade relativa do tratado, entendendo que o legislador interno não pretendeu violar o tratado, exceto nos casos em que o fizer claramente, hipótese em que a lei interna prevalecerá;

b) superioridade do tratado sobre a lei mais recente em data e

c) superioridade do tratado sobre a norma interna, ligando-a, porém, a um controle jurisdicional da constitucionalidade da lei. 
P. ex. Pacto de São José - conflita com art. 5º, LXVII da CF. Tal Pacto não pode contrapor-se ao art. 5o, LXVII da CF (cláusula pétrea) nem às normas infraconstitucionais especiais que regem a matérias por ser norma geral aplicável a fato interjurisdicional, que envolva pessoas pertencentes aos países signatários. Se o art. 5으, LXVII, da CF (Cláusula pétrea) prevê prisão civil para depositário infiel, isso deverá ser respeitado mesmo que a EC n.43/2004 tenha incluído o § 3ำ ao 5 CF, dispondo que tratado e convenção internacional sobre direitos humanos aprovados no Congresso Nacional será equiparado à Emenda Constitucional, isto porque por força do art. $60, \S 4^{\circ}$ da $\mathrm{CF}$, cláusula pétrea é insuscetível de emenda.

Apesar disso a Súmula vinculante n. 25 do STF entendeu que é "ilícita a prisão civil de depositário infiel qualquer que seja a modalidade de deposito". Teria tal Sumula força para alterar a cláusula pétrea da CF, se nem o Poder Constituinte Derivado a tem? Será que o transconstitucionalismo dos direitos humanos justificaria alteração de cláusula pétrea pelo judiciário? Contudo devemos respeitar tal decisão, por ser coisa julgada, por força do CF art. 5ํ, XXXVI, ante a regra de calibragem, que faz com que a CF recepcione a inconstitucionalidade: devemos respeitar a coisa julgada.

\section{ANTINOMIAS DE SEGUNDO GRAU E OS METACRITÉRIOS PARA SUA SOLUÇÃO}

Não se pode olvidar situações em que surgem antinomias entre os próprios critérios quando a um conflito de normas seriam aplicáveis dois critérios, que, contudo não poderiam ser ao mesmo tempo utilizados na solução da antinomia, pois a aplicação de um levaria à preferência de uma das normas e a de outro resultaria na escolha da outra norma.

Ter-se-á antinomia de segundo grau, quando houver conflito entre os critérios:

a) hierárquico (CF, art. 59) e cronológico (LINDB, art. $2^{\circ}, \S 1^{\circ}$ ) , hipóteses em que sendo uma norma anterior - superior antinômica a uma posterior-inferior, pelo 
critério hierárquico deve-se optar para primeira e pelo cronológico, pela segunda. $\mathrm{O}$ metacritério lex posterior inferiori non derogat priori superiori resolverá o problema.

Prevalecerá o hierárquico por ser mais forte do que o cronológico, visto que a competência se apresenta mais sólida do que a sucessão no tempo e, além disso, o cronológico só será válido para normas que se encontram no mesmo escalão;

b) da especialidade (CF. art. $\left.5^{\circ}\right)$ e o cronológico (LINDB, art. $2^{\circ} \S 1^{\circ}$ ), se houver norma anterior - especial conflitante com uma posterior - geral. Seria a primeira preferida pelo critério da especialidade e a segunda pelo critério cronológico. Valerá o metacritério lex posterior generalis non derogat priori speciali, segundo o qual o critério da especialidade prevaleceria sobre o cronológico.

Em regra, deverá prevalecer o da especialidade por ser o mais forte.

c) hierárquico (CF, art. 59) e o da especialidade (CF. art. 5o), no caso de uma norma superior - geral ser antinômica a uma inferior - especial, em que prevalece a primeira, aplicando-se o critério hierárquico e a segunda, utilizando-se o da especialidade. Não será possível estabelecer um metacritério, preferindo um deles. Teoricamente deveria prevalecer o hierárquico, pois uma lei constitucional geral deverá prevalecer sobre uma lei ordinária especial. Mas, na prática, às vezes, pelo princípio da justiça dever-se-á aplicar a norma especial, tratando igualmente o que é igual e desigualmente o que é desigual.

P. ex. o CC. Art. 1228, §§ 4º e 5ํ dispõe:

O proprietário tem a faculdade de usar, gozar e dispor da coisa e o direito de reavê-la do poder de quem quer que injustamente a possua ou detenha. $\S$ 4ㅇ $\mathrm{O}$ proprietário também pode ser privado da coisa se o imóvel reivindicado consistir em extensa área, na posse ininterrupta e de boa-fé, por mais de 5 anos, de considerável numero de pessoas e estas nela houverem realizado, em conjunto ou separadamente obras e serviços considerados pelo juiz de interesse social e econômico relevante. § $5^{\circ}$ No caso do parágrafo antecedente, o juiz fixará a justa indenização devida ao proprietário, pago o preço, valerá a sentença como titulo para o registro de imóvel e nome dos possuidores. Trata-se da desapropriação judicial pela posse-trabalho, motivado por interesse social e econômico relevante, que ante o disposto no art. 5, XXII da CF, seria uma afronta ao direito de propriedade, e no art. 5o, XXIV, que só admite desapropriação administrativa, não sendo possível estabelecer um metacritério, preferindo o especialidade ou o hierárquico. Tais critérios são igualmente fortes, resguardados constitucionalmente, já que o critério da especialidade (tratamento desigual ao desigual) é a segunda parte do princípio da 
isonomia (art. $5^{\circ}$ caput da CF). Surgindo uma antinomia real ou lacuna de conflito remetendo o intérprete e o aplicador a uma interpretação corretiva equitativa, optando pela mais justa, atende-se aos arts. $4^{\circ}$ e $5^{\circ}$ da LINDB, que os conduzirá à aplicação do principio geral de direito da função social da propriedade (CF, art. 5, XXIII), fazendo com que haja supremacia do critério da especialidade (CC, art. 1228 , $\S \S 4^{\circ}$ e $5^{\circ}$ ) e pelo mais alto principio da justiça suum cuique tribuere, baseado na interpretação de que o que é igual deve ser tratado igualmente e o que é diferente, de maneira diferente (DINZ, 2014, p.80-83).

\section{SOLUÇÃO DAS ANTINOMIAS REAIS}

A antinomia real decorre da incompletude de meio de sua solução, que conduz à conclusão de que o conflito normativo não poderá ser solucionado por critérios lógicos, mas poderá ser:

a) suprimido pela edição de uma norma derrogatória, que estabeleça que, em caso de antinomia, uma das duas ou ambas perdem a validade (KELSEN, 1962, p.228-355). Tal derrogação não está isenta do periculum antinomiae, pois a norma que suprimir a antinomia poderá dar origem a um novo conflito e

b) resolvido, no caso em julgamento, pelo Judiciário mediante emprego de uma interpretação corretivo - equitativa ou correção. Não se resolve a colisão normativa, mas o caso concreto submetido à apreciação judicial, aplicando-se os arts. $4^{\circ}$ e $5^{\circ}$ da LINDB, fazendo uso por ex. dos princípios gerais de direito e dos valores predominantes na sociedade.

\section{POSSIBILIDADE DE APLICAÇÃO DA TEORIA DO DIÁLOGO DAS FONTES NA SOLUÇÃO DAS ANTINOMIAS REAIS POR MEIO DE INTERPRETAÇÃO CORRETIVO - EQUITATIVA}

$\mathrm{Na}$ antinomia real não há solução unívoca, por isso há discricionariedade do órgão aplicador, que ao fazer uso dos arts $4^{\circ}$ e $5^{\circ}$ LINDB, pode hoje aplicar uma das normas conflitantes, e amanhã outra, optando pela mais favorável ao ler as normas sob a luz dos valores vigentes na sociedade.

Daí o grande papel da ideologia nos casos de antinomia real (FERRAZ JR, 1973, p. 152-158; DINIZ, 2014. p. 70 e 71; MIEDZIANAGORA, 1973. p. 79). 
A ideologia, conceito axiológico, que tem por objeto valorar os valores, permitirá solucionar a antinomia real, pois mostrará as fontes geradoras, valorando diretamente certos valores, determinando as finalidades do ordenamento jurídico, possibilitando o controle da mens legis, indicando os pontos de partida de uma argumentação jurídica.

A interpretação corretivo equitativa não constitui uma atividade passiva, pois não se deve estudar e aplicar os textos normativos ao pé da letra, mas sim em atenção ao diálogo das fontes, à realidade social subjacente e ao valor que confere sentido a esse fato, apreciando as pautas estimativas informadoras da ordem jurídico-positiva.

Requer a hermenêutica sensibilidade e prudência objetiva, exigindo que o jurista e $\mathrm{o}$ aplicador condicionem sua interpretação às balizas contidas no ordenamento jurídico e à técnica da ponderação (CPC, art. 489, § $2^{\circ}$ ), verificando se os resultados práticos correspondem a fins e valores, se houver p. ex., conflito entre normas relativas a direitos fundamentais.

De modo que entre duas normas plenamente justificáveis deve-se opinar pela que permitir a aplicação do direito com prudência objetiva e justiça, buscando a flexibilidade do entendimento razoável do preceito e não a lógica do raciocínio matemático.

Os arts. $4^{\circ}$ e $5^{\circ}$ da LINDB fornecem junto com a teoria do diálogo das fontes de Erik Jayme critérios hermenêuticos para a correção do conflito real de normas, constituindo uma válvula de segurança que possibilita solucionar ou aliviar aquela antinomia real.

Será que a teoria do diálogo das fontes conduziria à superação dos critérios cronológico (LINDB, art. $2 \S 1^{\circ}$ ), hierárquico (CF art. 59 e LINDB) normativos e o da especialidade ( $\mathrm{CF}$ art. $5^{\circ}$ ) para resolver antinomias aparentes?

Parece-nos, que não, se tais critérios são oriundos de normas (CF arts. 59 e $5^{\circ}$ e art. $2^{\circ} \S 1$ da LINDB), uma teoria hermenêutica não teria força para isso.

Não se pode substituir os critérios normativos previstos na CF e em lei especial, que resolvem antinomias aparentes pela teoria diálogo das fontes. 
Mas poder-se-á utilizar a teoria do diálogo das fontes: a) na interpretação corretiva - equitativa para solução de antinomia real ( de $1^{\circ}$ ou $2^{\circ}$ grau), ou de lacunas de colisão, b) no preenchimento de lacunas normativas, axiológicas e ontológicas e c) na subsunção, por meio da interpretação sistemática.

A teoria hermenêutica do diálogo das fontes de Erik Jayme, no nosso entender, em que pesem as opiniões em contrário, poderá ser usada: 1) na interpretação sistemática, p. ex. a) na área contratual ante a similitude principiológica, relativa à função social do contrato e boa-fé objetiva, nada obsta que se aplique o CDC nas relações de transporte, se forem benéficas. (Enunciado 369 da IV Jornada de Direitos) e b) num seguro saúde (serviço de consumo) é possível aplicar o CDC, CC e a Lei n. 9656/1998 (que o rege). Também nas relações trabalhistas, o art. $8^{\circ} \mathrm{CLT}$, o direito comum (D Civil) também é fonte do Direito do Trabalho. Pela EC 45/2004, a justiça do trabalho pode tratar de casos de responsabilidade civil por acidente do trabalho. Diálogo das fontes leva a constitucionalização de todos os ramos do direito. É preciso dialogar sempre com a $\mathrm{CF}$, aplicando-se p. ex. os princípios constitucionais da dignidade humana, da função social da propriedade, da solidariedade etc. 2. na integração de lacunas, e na interpretação corretiva de antinomias reais, principalmente na aplicação dos arts. 4 e $5^{\circ}$ da LINDB, que solucionam problemas alusivos às lacunas e à antinomia real. Tal diálogo permitirá que se aplique duas ou mais normas, complementar ou subsidiariamente, ou que se opte por uma das normas conflitantes, desde que seja a mais favorável ou mais justa ao caso ou à parte mais vulnerável, tendo como vetores o respeito aos direitos fundamentais e dignidade da pessoa humana.

Todas as técnicas interpretativas podem ser empregadas simultaneamente ou subsidiariamente, fazendo uso do diálogo das fontes, condenando-se a supremacia de uma sobre a outra.

Cada preceito normativo significa algo situado no todo do ordenamento jurídico, implicando apreciação de fatos e valores.

Ao admitir essa visão interpretativa e integrativa da norma, reconhece-se ao intérprete o papel de criação epistemológica e, ao aplicador, o de criação real no processo hermenêutico. 
Esse é o grande desafio do jurista e do aplicador: aplicação justa do diálogo das fontes seja: a) no diálogo sistemático de coerência, em que uma norma serve de base contratual para outra, tendo por suporte o fundamento teleológico das normas ( p. ex. questão transporte pode obter subsídios no CC e no CDC e em tratados internacionais);

b) no diálogo de complementariedade e subsidiariedade uma norma poderá incidir na aplicação de outra de forma complementar (direta) ou subsidiária (indireta), p. ex. poder-se-á aplicar complementarmente no que atina às clausulas abusivas tanto o CC art. 424 como o art. 51 CDC. Quanto à oferta de consumo (CDC, arts. 30 e 35) só se aplicará subsidiariamente o CC art. 429 no que couber, em caso de lacuna (diálogo de subsidiariedade). Se na relação de consumo houver dano à honra, à saúde, incidirão também as normas de Cod. Civil sobre responsabilidade civil e

c) no diálogo de coordenação e adaptação sistemática, que aponta influência de norma especial sobre a geral e vice versa. P. ex. o princípio da boa-fé objetiva pode ser influenciado pelo CDC (OLIVEIRA, 2004, p.15-54).

É possível um diálogo de leis, simultânea, prioritária ou subsidiariamente para alcançar a ratio, a finalidade social (LINDB) pretendida em busca do critério do justo, pois os fins (Engisch) da norma podem estar dentro dela, em outras normas e até fora dela nos valores objetivos (não subjetivos) e fatos positivados, pois a conduta é modelada pela norma para educar pessoas (DINIZ, 2017, p.459-460).

$\mathrm{Na}$ interpretação sistemática relaciona-se uma norma com outra relativa ao mesmo objeto. O sistema jurídico, criado pelo jurista, não é uno, mas um conjunto harmônico e interdependente. O hermeneuta deve relacionar umas normas a outras até vislumbrar-lhes o sentido e o alcance.

Nunca se deve ler $\circ \S 2^{\circ}$ sem ler antes 0 § $1^{\circ}$, nunca se deve ler um só artigo, leia-se também o vizinho. Deve-se comparar o artigo com outros do mesmo diploma legal ou de leis diversas, mas referentes ao mesmo objeto.

A interpretação não é pura arte dialética, não se desenvolve como método geométrico num circulo de abstrações, porque o interprete deve buscar as exigências da vida. Pelo art. $5^{\circ}$ da LINDB, deve-se procurar o fim, a ratio do preceito 
normativo para, a partir dele, determinar seu sentido. A percepção do fim exige não o estudo de cada norma isoladamente, mas sua análise no ordenamento jurídico como um todo.

Diálogo das fontes é, tão somente, mero instrumento interpretativo, na subsunção, na integração de lacunas e na correção da antinomia reais.

Trata-se de ferramenta hermenêutica para interpretar normas de forma coordenada e sistemática, em consonância com a CF.

Diálogo porque há uma aplicação concomitante de normas dando solução mais justa (art. 5o, da LINDB), protegendo p. ex. a parte vulnerável, buscando a dignidade da pessoa humana e a aplicação dos direitos fundamentais.

Se assim é, deixo no ar uma questão:

Qual a novidade da teoria do diálogo das fontes, se sempre existiu na hermenêutica jurídica?

O grande desafio é aplicar corretamente as fontes em diálogo de forma justa para que haja uma interpretação, integração e correção coerente sistematicamente. Evitando, assim, o ativismo judicial, que vem conduzindo o Poder Judiciário a invadir área do Legislativo e até do Poder Constituinte derivado, ao regulamentar, ao arrepio da lei e da Constituição Federal, determinados assuntos, criando direito novo, ao fazer uso na correção de antinomia real, na integração da lacunas e na interpretação sistemática de argumentos que levam a crer que a inovação já estava contida no ordenamento jurídico.

A discricionariedade judicial não pode ser aleatória, nem desmesurada, pois deve ficar limitada às peculiaridades de cada caso, às normas a ele aplicáveis, ao comando constitucional, não tendo força para criar direito novo em país de Constituição rígida como o nosso, e deve ater-se em caso de lacuna e antinomia real aos arts. $4^{\circ}$ e $5^{\circ}$ LINDB, fazendo, conforme o caso, uso ou não do diálogo das fontes, tendo como parâmetro os direitos fundamentais e o respeito à dignidade humana.

\section{CONCLUSÃO}


O sistema jurídico deve ser coerente, logo a existência de antinomia real conduz o jurista ou o aplicador a uma interpretação corretivo - equitativa, para solucionar aquele conflito, que pressupõe que as normas inconsistentes sejam válidas, mediante a aplicação dos arts. 4ำ e $5^{\circ}$ da LINDB, em busca do valor justum, pelo qual prefere entre duas normas incompatíveis a mais justa.

O legislador poderá eliminar tal conflito pela derrogação, por meio de edição de uma terceira norma, que negue a validade de uma ou de ambas as normas.

\section{REFERÊNCIAS}

BOBBIO. Des criterès pour résondre les antinomies. in Les antinomies en droit. Bruxelles: Perelman (pub.), Bruylant, 1965.

BOBBIO. Teoria dell’ordinamento jurídico. Torino: Giappichelli, 1960.

$\mathrm{BUCH}$. Conception dialectique des antinomies juridiques. in Les antinomies en droit. Bruxelles: Perelman (pub.), Bruylant, 1965.

DINIZ, M.H. Compendio de introdução à ciência do direito. São Paulo: Saraiva, 2017.

. Conflito de normas. São Paulo: Saraiva, 2014.

ENGISCH, Karl. Introdução ao pensamento jurídico. Lisboa: Caloustegulbenkian, 1964.

FERRAZ JR., Tercio Sampaio. Antinomia. Enciclopédia Saraiva do Direito, V. 7, 1978a.

. Direito, retórica e comunicação. São Paulo: Saraiva, 1973.

. Teoria norma jurídica. Rio de Janeiro: Forense, $1978 \mathrm{~b}$.

GAVAZZI. Delle antinomie. Torino: Giappichelli, 1959.

KELSEN. Derogation. Essays in jurisprudence in Honor of Roscoe Pound. New York: Ralph A. Newman, 1962.

KLUG, Ulrich. Logica jurídica. Caracas: s/e, 1961. p. 129. 
. Observations sur le probléme des lacunes em droit. in Le probléme des lacunes in droit. Perelman (coord.). Bruxelles: s/e, 1965.

LIMA MARQUES, Claudia. Superação das antinomias pelo diálogo das fontes: o modelo brasileiro de coexistência entre o código de defesa do Consumidor e o Código Civil de 2002. Revista da Escola Superior da Magistratura de Sergipe, n.7, p. 15-54 (2004).

MAREK. Les rapports entre le droit international et le droit interne a la lumière de la jurisprudence de la CPII. Revue Générale de Droit International Public, n. 2, p. 260-298, 1962.

MAXIMILIANO, Carlos. Hermenêutica e aplicação do direito. Rio de janeiro: Freitas Bastos, 1965.

MERKL. Allgemunès Verwaltungsrecht. s/l: s/e, 1927.

MERKL. Die Rechtseinheidt des osterreichschen staates. Archiv des offentlichex Rechts, 37: 75, 1917.

MIEDZIANAGORA. Droit positif et ideologie. in Études de logique juridigue. Bruxelles: Bruylant, 1973.

OLIVEIRA, Veronica B. Superação do clássico método de resolução de conflitos (antinomias): aplicação da teoria do diálogo das fontes. Disponível em: HTTPS://jus.com.br/artigos/48357/.

PERELMAN, Chaim. Les antinomies en droit. Essai de synthèse. in Les antinomies en droit. Bruxelles: Perelman (pub.), Bruylant, 1965.

REALE. Miguel. Lições preliminares de direito. São Paulo: Bushatsky, 1973.

ROSENTREICH, Nathan. On a constructing a philosophical system. s/l: s/e, 1963.

ROSS, Alf. Sobre el derecho y la justicia. Buenos Aires: s/e, 1970.

SALMON. Les antinomies en droit international public. in Les antinomies en droit. Bruxelles: Perelman (pub.), Bruylant, 1965.

SILANCE. Quelques exemples d'antinomies et essai de classement. in Les antinomies en droit. Bruxelles: Perelman (pub.), Bruylant, 1965.

VANDER ELST. Antinomies em droit internacional prive. in Les antinomies en droit. Bruxelles: Perelman (pub.), Bruylant, 1965. p. 138. 